Check for updates

Cite this: RSC Adv., 2017, 7, 34722

Received 21st May 2017

Accepted 5th July 2017

DOI: $10.1039 / \mathrm{c} 7 \mathrm{ra05711c}$

rsc.li/rsc-advances

\title{
Highly efficient heterogeneous copper-catalyzed decarboxylative cross-coupling of potassium polyfluorobenzoates with aryl halides leading to polyfluorobiaryls $\dagger$
}

\author{
Yang Lin, ${ }^{a}$ Mingzhong Cai, (D) *b Zhiqiang Fang ${ }^{a}$ and Hong Zhao*a
}

\begin{abstract}
The heterogeneous decarboxylative cross-coupling reaction of potassium polyfluorobenzoates with aryl iodides and bromides was achieved in diglyme or DMAc at 130 or $160{ }^{\circ} \mathrm{C}$ in the presence of $10-20$ mol\% of a 1,10-phenanthroline-functionalized MCM-41-immobilized copper(1) complex, [MCM-41-PhenCul], yielding a variety of polyfluorobiaryls in good to excellent yields. This heterogeneous copper(I) complex could easily be prepared via a simple procedure from commercially readily available and inexpensive reagents, exhibited the same catalytic activity as the homogeneous Cul/Phen system, and was recovered by filtration of the reaction solution and recycled at least 8 times without significant loss of catalytic activity.
\end{abstract}

\section{Introduction}

Polyfluorobiaryls are important molecules in the pharmaceutical chemistry ${ }^{1}$ and materials science ${ }^{2}$ and are often used as starting materials in organic synthesis. ${ }^{3}$ Subsequently, a variety of methods have been developed to form polyfluorobiaryls. The traditional methods involve the palladium- or copper-catalyzed cross-coupling reactions of pre-functionalized polyfluoroarenes with aryl halides, which require the use of expensive organometallic starting materials such as boronic acids, ${ }^{4}$ borate salts, ${ }^{5}$ stannanes, ${ }^{6}$ and copper species. ${ }^{7}$ Besides these methods, the palladium- or copper-catalyzed $\mathrm{C}-\mathrm{H}$ arylation of polyfluoroarenes with aryl halides, ${ }^{8}$ arylboronic acids, ${ }^{9}$ organosilicon reagents, ${ }^{10}$ arenediazonium tetrafluoroborates, ${ }^{11}$ and aryliodine(III) diacetates,${ }^{12}$ has provided an alternative approach to the synthesis of polyfluorobiaryls. Transition-metal-catalyzed decarboxylative cross-couplings using carboxylic acids as aryl sources are an attractive strategy for the construction of biaryl bonds because this method does not use expensive and sensitive organometallic reagents, and generates $\mathrm{CO}_{2}$ instead of organometallic byproducts that are formed in Suzuki-Miyaura, Stille, Kumada, and Negishi reactions. ${ }^{13}$ Furthermore, structurally diverse carboxylic acids are often inexpensive and commercially readily available. Recently, palladium-, nickel-

${ }^{a}$ School of Chemistry \& Chemical Engineering, Guangdong Cosmetics Engineering \& Technology Research Center, Guangdong Pharmaceutical University, Guangzhou 510006, P. R. China. E-mail: zhaohong1001@sina.com

${ }^{b}$ College of Chemistry \& Chemical Engineering, Jiangxi Normal University, Nanchang 330022, P. R. China.E-mail:mzcai@jxnu.edu.cn

$\dagger$ Electronic supplementary information (ESI) available. See DOI: 10.1039/c7ra05711c and copper-catalyzed decarboxylative cross-couplings of polyfluorobenzoic acids or polyfluorobenzoate salts with aryl halides $^{14}$ and palladium-catalyzed decarboxylative crosscoupling of aromatic carboxylic acids with polyfluoroarenes ${ }^{15}$ have been reported to be highly efficient methods for the synthesis of polyfluorobiaryls.

Although significant progress has been achieved in construction of polyfluorobiaryls by homogeneous Pd-, Ni- and $\mathrm{Cu}$-catalyzed decarboxylative cross-coupling reactions, the use of expensive palladium catalysts and about $10-20 \mathrm{~mol} \%$ of nickel or copper catalysts has limited their applications in largescale syntheses and industrial processes because homogeneous catalysis suffers from the problematic separation of the catalyst from the product for re-use. ${ }^{16}$ Moreover, homogeneous catalysis might result in heavy metal contamination of the desired isolated product, which restricts the application of such systems in electronics and biomedicine. The heterogenization of the existing homogeneous transition-metal catalysts appears to be a logical solution to these problems. ${ }^{17}$ There has been considerable interest in the development of heterogeneous catalytic systems that can be easily recycled whilst maintaining the inherent activity of the catalytic center. However, to the best of our knowledge, no examples of heterogeneous palladium-, nickel- and copper-catalyzed synthesis of polyfluorobiaryls have been reported until now.

Mesoporous MCM-41 materials have recently emerged as promising supports for immobilization because of their large and uniform pore sizes, ultrahigh surface areas, big pore volumes and rich silanol groups in the inner walls. ${ }^{18}$ To date, some functionalized MCM-41-immobilized palladium, ${ }^{19}$ rhodium, ${ }^{20}$ molybdenum, ${ }^{21}$ gold $^{22}$ and copper ${ }^{23}$ complexes have 


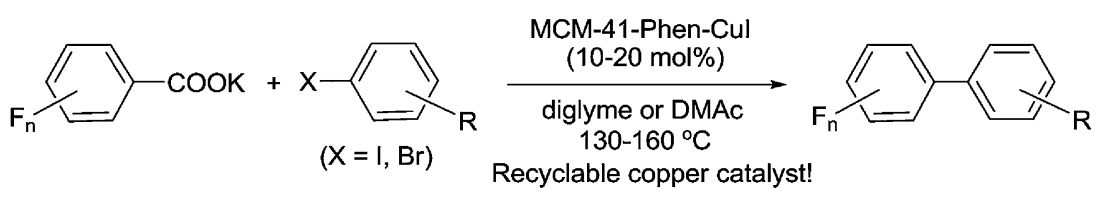

Scheme 1 Synthesis of polyfluorobiaryls via heterogeneous copper(l)-catalyzed decarboxylative cross-coupling of potassium polyfluorobenzoates with aryl halides.

been successfully used as potentially green and sustainable catalysts in organic reactions. Recently, we reported the first synthesis of MCM-41-immobilized 1,10-phenanthroline-copper(I) complex [MCM-41-Phen-CuI] and found that it is a highly efficient and recyclable heterogeneous catalyst for the $\mathrm{C}-\mathrm{O}$ coupling reaction between aryl iodides and aliphatic alcohols. ${ }^{24}$ In continuing our efforts to develop greener synthetic pathways for organic transformations, ${ }^{19 d-f, 23,24}$ herein we wish to report a highly efficient, heterogeneous copper(I)-catalyzed decarboxylative cross-coupling of potassium polyfluorobenzoates with aryl halides leading to polyfluorobiaryls in good to excellent yields (Scheme 1).

\section{Results and discussion}

A series of MCM-41-immobilized 1,10-phenanthroline-copper(I) or (II) complexes [MCM-41-Phen-CuX ${ }_{n}$ ] were easily prepared according to the procedure summarized in Scheme $2 .{ }^{24}$ Firstly, the mesoporous MCM-41 (ref. 25) was condensed with 1-(1,10phenanthrolin-5-yl)-3-(3-(triethoxysilyl)propyl)urea ${ }^{26}$ in toluene under reflux for $24 \mathrm{~h}$, followed by the silylation with $\mathrm{Me}_{3} \mathrm{SiCl}$ in toluene at room temperature for $24 \mathrm{~h}$ to afford the 1,10phenanthroline-functionalized MCM-41 [MCM-41-Phen]. The latter was then reacted with copper salts in acetone under reflux for $24 \mathrm{~h}$ to generate a series of MCM-41-immobilized 1,10phenanthroline copper(I) or (II) complexes [MCM-41-Phen$\left.\mathrm{CuX}_{n}\right]$ as light green powders.

In our initial screening experiments, the reaction of $\mathrm{C}_{6} \mathrm{~F}_{5} \mathrm{COOK}$ with $\mathrm{PhI}$ was investigated to optimize the reaction conditions, and the results are summarized in Table 1 . First, the effect of various immobilized copper complexes on the model reaction was examined by using DMAc as solvent at $130{ }^{\circ} \mathrm{C}$ (Table 1, entries 1-6). It is evident that lower yields were obtained when MCM-41-Phen-CuCl [A], MCM-41-Phen-CuBr [B], MCM-41-Phen-CuCl ${ }_{2}$ [D], and MCM-41-Phen- $\mathrm{CuBr}_{2}$ [E] were used as catalysts, and MCM-41-Phen-CuI [C] could give a moderate yield (entry 3), whilst MCM-41-Phen- $\mathrm{Cu}(\mathrm{OAc})_{2}[\mathbf{F}]$ afforded a low yield, so MCM-41-Phen-CuI [C] was finally selected as the catalyst for the reaction. Our next studies focused on the effect of solvent on the model reaction and a significant solvent effect was observed (Table 1, entries 3 and 7-10). When NMP, DMF and DMSO were used as solvents, low yields were obtained (entries 7, 9 and 10). To our delight, an excellent yield of $97 \%$ was achieved when diglyme was used as the solvent (entry 8). A possible explanation for this result is that diglyme can coordinate to potassium cation, which facilitates the reaction between the MCM-41-Phen-CuI complex and $\mathrm{C}_{6} \mathrm{~F}_{5} \mathrm{COO}^{-}$. The effect of temperature on the model reaction was also examined (Table 1, entries 8 and 11-13). For the temperatures tested [120, 130, 140 and $\left.150{ }^{\circ} \mathrm{C}\right], 130{ }^{\circ} \mathrm{C}$ was the best choice (entry 8), and other temperatures were substantially less effective (entries 11-13). Finally, the amount of the immobilized copper catalyst was screened, and $10 \mathrm{~mol} \%$ loading of copper was found to be optimal, a lower yield was observed and a longer reaction time was required when the amount of the catalyst was decreased (entry 14). Increasing the amount of the copper catalyst could shorten the reaction time, but did not improve the yield of $\mathbf{3 a}$ obviously (entry 15). When a homogeneous $\mathrm{CuI} / \mathrm{Phen}$ was used as the catalyst, the desired product 3a was also isolated in $98 \%$ yield (entry 16), which indicating that catalytic activity of MCM-41-Phen-CuI was comparable to that of
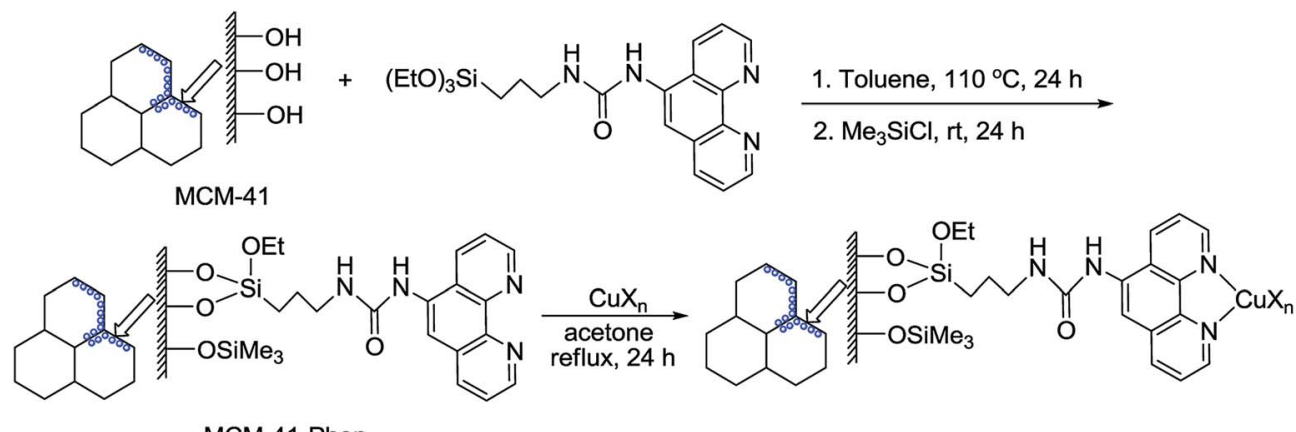

MCM-41-Phen

MCM-41-Phen-CuCl (A), $\mathrm{CuX}_{\mathrm{n}}=\mathrm{CuCl}$ MCM-41-Phen-CuBr (B), $\mathrm{CuX}_{n}=\mathrm{CuBr}$ MCM-41-Phen-Cul (C), $\mathrm{CuX}_{n}=\mathrm{Cul}$

MCM-41-Phen-CuCl 2 (D), $\mathrm{CuX}=\mathrm{CuCl}_{2}$ MCM-41-Phen-CuBr 2 (E), $\mathrm{CuX}_{\mathrm{n}}=\mathrm{CuBr}_{2}$ $\mathrm{MCM}-41-\mathrm{Phen}-\mathrm{Cu}(\mathrm{OAC})_{2}(\mathbf{F}), \mathrm{CuX} \mathrm{n}_{\mathrm{n}}=\mathrm{Cu}(\mathrm{OAc})_{2}$

Scheme 2 Preparation of MCM-41-immobilized 1,10-phenanthroline copper(I) or (II) complexes. 
Table 1 Screening of reaction conditions for the reaction of $\mathrm{C}_{6} \mathrm{~F}_{5} \mathrm{COOK}$ with $\mathrm{Phl}^{a}$

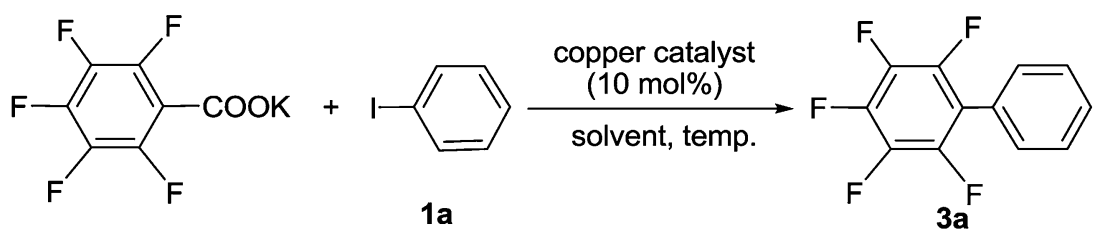

\begin{tabular}{|c|c|c|c|c|c|}
\hline Entry & Copper catalyst & Solvent & Temp. $\left({ }^{\circ} \mathrm{C}\right)$ & Time (h) & Yield $^{b}(\%)$ \\
\hline 1 & $\mathbf{A}$ & DMAc & 130 & 24 & 39 \\
\hline 2 & B & DMAc & 130 & 24 & 44 \\
\hline 3 & $\mathbf{C}$ & DMAc & 130 & 24 & 49 \\
\hline 4 & D & DMAc & 130 & 24 & 38 \\
\hline 5 & $\mathbf{E}$ & DMAc & 130 & 24 & 40 \\
\hline 6 & $\mathbf{F}$ & DMAc & 130 & 24 & 18 \\
\hline 7 & C & NMP & 130 & 24 & 41 \\
\hline 8 & C & Diglyme & 130 & 24 & 97 \\
\hline 9 & C & DMF & 130 & 24 & 37 \\
\hline 10 & C & DMSO & 130 & 24 & 24 \\
\hline 11 & $\mathbf{C}$ & Diglyme & 140 & 20 & 93 \\
\hline 12 & C & Diglyme & 150 & 12 & 88 \\
\hline 13 & C & Diglyme & 120 & 30 & 79 \\
\hline $14^{c}$ & $\mathbf{C}$ & Diglyme & 130 & 48 & 82 \\
\hline $15^{d}$ & C & Diglyme & 130 & 12 & 98 \\
\hline 16 & CuI/Phen & Diglyme & 130 & 24 & 98 \\
\hline $17^{e}$ & C & Diglyme & 130 & 30 & 82 \\
\hline
\end{tabular}

${ }^{a}$ Reaction was performed with $\mathrm{C}_{6} \mathrm{~F}_{5} \mathrm{CO}_{2} \mathrm{~K}(0.75 \mathrm{mmol}), \mathbf{1 a}(0.5 \mathrm{mmol})$ and copper catalyst $(0.05 \mathrm{mmol})$ in solvent $(0.5 \mathrm{~mL})$ under Ar. ${ }^{b}$ Isolated yield based on 1a. ${ }^{c} 5$ mol\% MCM-41-Phen-CuI was used. ${ }^{d} 20$ mol\% MCM-41-Phen-CuI was used. ${ }^{e} 1.0$ equiv. of $\mathrm{C}_{6} \mathrm{~F}_{5} \mathrm{CO}_{2} \mathrm{~K}$ was used.

$\mathrm{CuI} /$ Phen combination. When 1.0 equiv. of $\mathrm{C}_{6} \mathrm{~F}_{5} \mathrm{COOK}$ was used, the yield of 3 a was decreased to $82 \%$ (entry 17). Therefore, the optimal catalytic system involved the use of MCM-41-Phen$\mathrm{CuI}[\mathrm{C}](10 \mathrm{~mol} \%)$ and 1.5 equiv. of $\mathrm{C}_{6} \mathrm{~F}_{5} \mathrm{COOK}$ in diglyme at $130{ }^{\circ} \mathrm{C}$ under Ar for $24 \mathrm{~h}$ (Table 1, entry 8).

With the optimal reaction conditions established, we tried to investigate the scope and limitations of this heterogeneous copper-catalyzed decarboxylative cross-coupling reaction and the results are summarized in Table 2. As shown in Table 2, both electron-deficient and electron-rich aryl iodides $\mathbf{1 b} \mathbf{- 1} \mathbf{j}$ underwent the decarboxylative cross-coupling reaction with $\mathrm{C}_{6} \mathrm{~F}_{5} \mathrm{COOK}$ smoothly to afford the corresponding polyfluorobiaryls $\mathbf{3 b}-\mathbf{3 j}$ in $91-96 \%$ yields. The results indicated that the electronic natures of the substituents on benzene ring have limited influence on this heterogeneous copper-catalyzed decarboxylative cross-coupling reaction. The sterically congested electron-deficient aryl iodides such as 2-chloroiodobenzene 1k, methyl 2-iodobenzoate $\mathbf{1 l}$ and 2nitroiodobenzene $\mathbf{1 m}$ could also be successfully converted into the corresponding polyfluorobiaryls $\mathbf{3 k} \mathbf{k} \mathbf{3 m}$ in excellent yields. The electron-rich 2-iodotoluene $\mathbf{1 n}$ and 2-iodoanisole 10 showed slightly lower reactivity than the electron-deficient ortho-substituted iodobenzenes, however, the desired products 3n and 30 were also obtained in excellent yields by using 20 mol\% of MCM-41-Phen-CuI as catalyst. A range of functional groups such as methyl, methoxy, chloro, fluoro, trifluoromethyl, nitro, cyano and ester were well tolerated. In addition to phenyl iodides, heteroaryl iodides such as 3-, 2-, and 4-iodopyridines 1p-1r and 3-iodothiophene 1s also proved to be good coupling partners and gave the desired products $\mathbf{3 p - 3 s}$ in high yields. Notably, bulky 1-iodonaphthalene 1t could react with $\mathrm{C}_{6} \mathrm{~F}_{5}$ COOK effectively in the presence of $20 \mathrm{~mol} \%$ of MCM-41Phen-CuI to furnish the desired product 3t in $96 \%$ yield.

Encouraged by the above results, we further investigated the scope and the generality of the method by varying aryl iodides to aryl bromides and the results are listed in Table 3. Generally, the reactivity of aryl bromides was lower than that of aryl iodides. Under the conditions optimized for aryl iodides, the reaction of bromobenzene with $\mathrm{C}_{6} \mathrm{~F}_{5}$ COOK gave the desired product $3 \mathrm{a}$ in only $74 \%$ yield after $36 \mathrm{~h}$. However, the yield of $\mathbf{3 a}$ could be improved to $91 \%$ by increasing the amount of the catalyst to $20 \mathrm{~mol} \%$. As shown in Table 3, in the presence of 20 mol\% of MCM-41-Phen-CuI, a variety of aryl bromides bearing either electron-withdrawing or electron-donating groups underwent decarboxylative cross-coupling reactions with $\mathrm{C}_{6} \mathrm{~F}_{5} \mathrm{COOK}$ smoothly to give the corresponding polyfluorobiaryls $\mathbf{3 b} \mathbf{b} \mathbf{3 d}, \mathbf{3 u}, \mathbf{3 f}-\mathbf{3 i}$ and $\mathbf{3 v}$ in good to excellent yields. The electron-rich aryl bromides exhibited slightly lower reactivity than the electron-deficient ones and longer reaction times were required to complete the reactions. The ortho-substituted bromobenzenes such as 2-chlorobromobenzene and 2-bromotoluene also afforded the desired products $3 \mathbf{k}$ and $\mathbf{3 n}$ in excellent yields after $36 \mathrm{~h}$. In addition to aryl bromides, heteroaryl bromides proved to be also suitable substrates and could 
Table 2 Heterogeneous copper-catalyzed decarboxylative cross-coupling between potassium pentafluorobenzoate and aryl iodides ${ }^{a, b}$
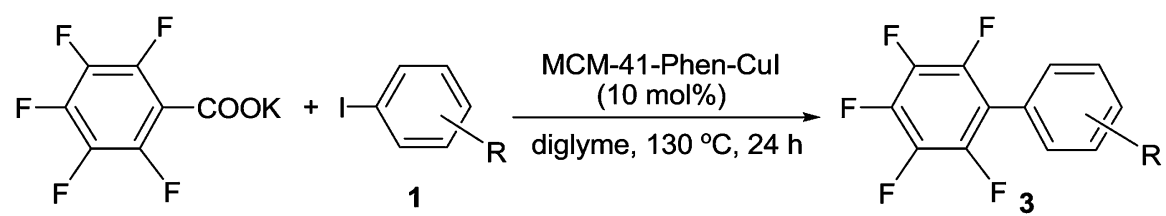<smiles>CC(C)(S)c1ccccc1</smiles>

$\mathrm{C}_{6} \mathrm{~F}_{5}$<smiles>[13CH3][13OH]</smiles><smiles>FC(F)(F)c1ccc(C(F)(F)F)cc1</smiles>

3f, $96 \%$<smiles>FC(F)(F)c1ccccc1Cl</smiles>

3k, $91 \%$<smiles>CC(C)(F)c1cccnc1</smiles>

$3 p, 91 \%$<smiles>O=[N+]([O-])c1cccc(S(=O)(=O)c2ccccc2)c1</smiles>

3g, $91 \%$<smiles>COC(OC)c1ccccc1S(=O)(=O)c1ccccc1</smiles>

3I, $96 \%$<smiles>CC(C)(F)c1ccccn1</smiles>

3q, $90 \%$<smiles></smiles>

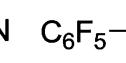<smiles>Clc1ccc([Sb])cc1</smiles><smiles>O=S(F)(F)(F)c1ccc(F)cc1</smiles>

3d, $94 \%$ 3c, $93 \%$ $\mathrm{C}_{6} \mathrm{~F}_{5}$

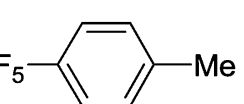<smiles>Cc1ccc(C(F)(F)F)cc1</smiles>
$\mathrm{OM}$<smiles>Cc1cccc(C(F)(F)F)c1</smiles>
3h, $95 \%$ 3i, $95 \%$ 3j, $93 \%$<smiles>O=[N+]([O-])c1ccccc1C(F)(F)F</smiles>

$3 \mathrm{~m}, 92 \%$<smiles>Cc1ccccc1C(F)(F)F</smiles>

$3 n,{ }^{c} 95 \%$<smiles>CC(C)(F)c1ccncc1</smiles>

$3 r, 89 \%$<smiles>CC(C)(F)c1ccsc1</smiles>

3s, $91 \%$<smiles>COc1ccccc1C(F)(F)F</smiles>

30, ${ }^{c} 94 \%$<smiles>FC(F)(F)c1cccc2ccccc12</smiles>

$3 t,{ }^{c} 96 \%$

${ }^{a}$ Reaction was performed with potassium pentafluorobenzoate $(0.75 \mathrm{mmol}), \mathbf{1}(0.5 \mathrm{mmol})$ and MCM-41-Phen-CuI $(0.05 \mathrm{mmol})$ in diglyme $(0.5 \mathrm{~mL})$ at $130{ }^{\circ} \mathrm{C}$ under Ar for $24 \mathrm{~h}^{b}{ }^{b}$ Isolated yield. ${ }^{c} 20 \mathrm{~mol} \%$ MCM-41-Phen-CuI was used.

undergo the decarboxylative cross-coupling reaction effectively to give the corresponding polyfluorobiaryls $\mathbf{3 p}, \mathbf{3 q}$ and $3 \mathbf{s}$ in high yields.
The scope of the reaction with respect to fluoroarene was also examined and the results are presented in Table 4 . Although diglyme plays an important role in the reactions with

Table 3 Heterogeneous copper-catalyzed decarboxylative cross-coupling between potassium pentafluorobenzoate and aryl bromides ${ }^{a, b}$

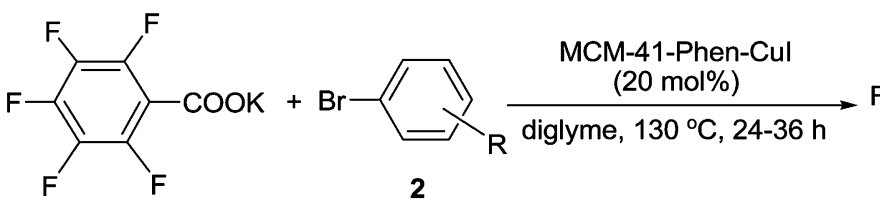<smiles>[R]Cc1cccc(-c2c(F)c(F)c(F)c(F)c2F)c1</smiles><smiles>[134S]c1ccccc1</smiles><smiles>O=[N+]([O-])c1ccc(S(=O)(=O)c2ccc([S+])cc2)cc1</smiles>

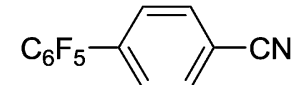<smiles>C1CCCCC1</smiles><smiles>Cc1ccccc1</smiles><smiles>c1ccccc1</smiles>

$3 d, 93 \%, 26 \mathrm{~h}$<smiles>FC(F)(F)c1ccc(C(F)(F)F)cc1</smiles>

b, $86 \%, 24 \mathrm{~h}$

$3 c, 92 \%, 24 \mathrm{~h}$

$\mathrm{C}_{6} \mathrm{~F}_{5}$<smiles>Cc1cccc(I)c1</smiles>
$\mathrm{NO}_{2}$

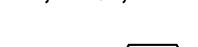<smiles>[SbH2-]CC[PbH2]</smiles><smiles>Cc1ccc(C)cc1</smiles><smiles>[SbH2]CC[PbH2]</smiles><smiles>COc1ccc(C)cc1</smiles>

$3 u, 94 \%, 24 \mathrm{~h}$<smiles>[R16][R6]([H])([H])CC</smiles><smiles>FC(F)(F)c1ccccc1Cl</smiles>

3k, $90 \%, 36 \mathrm{~h}$

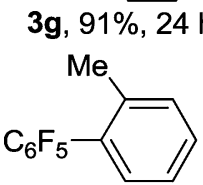

3n, $92 \%, 36$ h
$3 \mathrm{~h}, 92 \%, 36 \mathrm{~h}$

3i, $93 \%, 36$ h<smiles>CC(C)(F)c1cccnc1</smiles>

$3 p, 88 \%, 30 h$<smiles>FC(F)(F)c1ccccn1</smiles>

$3 q, 86 \%, 30 \mathrm{~h}$<smiles>Cc1cccc(S(=O)(=O)c2ccccc2)c1</smiles>

3v, $91 \%, 36 \mathrm{~h}$ Me

${ }^{a}$ Reaction was performed with potassium pentafluorobenzoate $(0.75 \mathrm{mmol}), 2(0.5 \mathrm{mmol})$ and MCM-41-Phen-CuI $(0.1 \mathrm{mmol}) \mathrm{in}$ diglyme $(0.8 \mathrm{~mL})$ at

${ }^{a}$ Reaction was performed with potassium pen
$130{ }^{\circ} \mathrm{C}$ under Ar for $24-36 \mathrm{~h} .{ }^{b}$ Isolated yield. 
Table 4 Heterogeneous copper-catalyzed decarboxylative cross-coupling between aryl iodides and other polyfluorobenzoates ${ }^{a, b}$

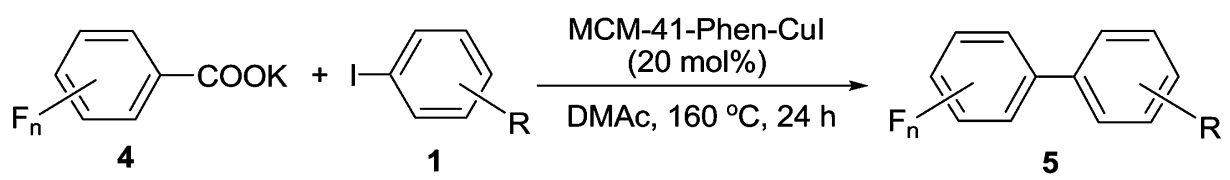<smiles>O=[N+]([O-])c1ccc(-c2c(F)cccc2F)cc1</smiles>

$5 a, 88 \%$<smiles>O=[N+]([O-])c1ccc(-c2c(F)ccc(F)c2F)cc1</smiles>
5f, $91 \%$<smiles>CC(C)(C)[13C](=O)c1c(F)cc(F)c(F)c1-c1ccc([N+](=O)[O-])cc1</smiles>
$\mathbf{5 k}, 86 \%$<smiles>Cc1c(F)c(F)c(-c2ccc([N+](=O)[O-])cc2)c(C(=O)OC(C)(C)C)c1F</smiles>

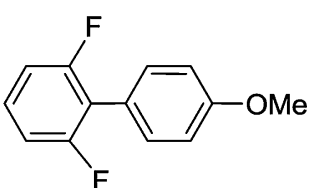

$5 \mathbf{b}, 73 \%$

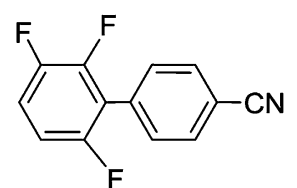

$5 \mathrm{~g}, 92 \%$

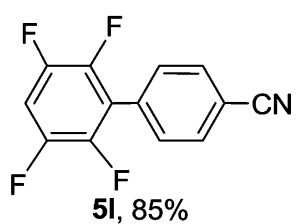

5 h, $79 \%$
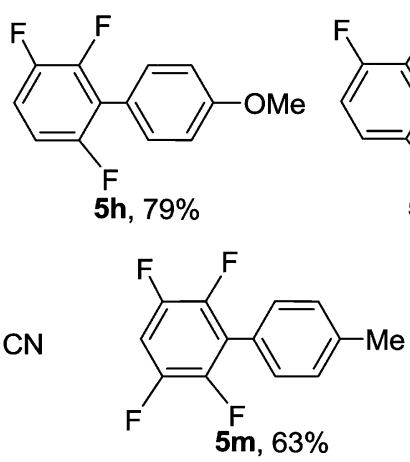

$5 \mathbf{i}, 69 \%$

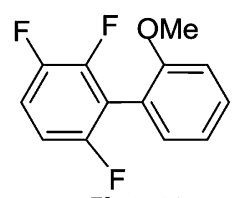

Fd, $81 \%$

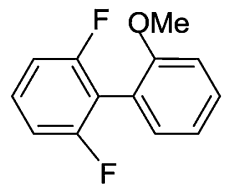

5e, $79 \%$

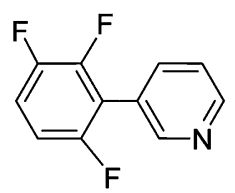

5 j, $82 \%$

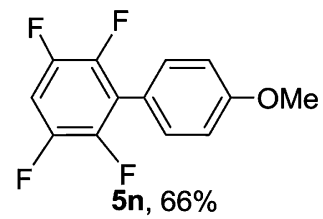

\footnotetext{
${ }^{a}$ Reaction was performed with $4(0.75 \mathrm{mmol}), \mathbf{1}(0.5 \mathrm{mmol})$ and MCM-41-Phen-CuI $(0.1 \mathrm{mmol})$ in DMAc $(0.8 \mathrm{~mL})$ at $160{ }^{\circ} \mathrm{C}$ under $\mathrm{Ar}$ for $24 \mathrm{~h}$.

${ }^{b}$ Isolated yield.
}

potassium pentafluorobenzoate, $N, N$-dimethyl acetamide (DMAc) can afford better results for fluoroarenes bearing fewer fluorine atoms. In addition, the use of $20 \mathrm{~mol} \%$ of MCM-41Phen-CuI and a high temperature of $160{ }^{\circ} \mathrm{C}$ were required due to their lower reactivity. Under the optimized reaction conditions, potassium monofluorobenzoate was found to be not suitable substrate and the reactions with aryl iodides generated traces of the desired products. This may be due to the fact that an ortho-F atom in potassium monofluorobenzoate can not activate the carboxylic group effectively. The decarboxylative cross-coupling reactions of potassium 2,6-difluorobenzoate $\mathbf{4 a}$ with both electron-poor and electron-rich aryl iodides proceeded smoothly to afford the corresponding 2,6-difluorobiaryls 5a-5e in good to high yields. The coupling reactions could tolerate strong electron-withdrawing or electron-donating groups and could also tolerate ortho substitution. In addition, tri- and tetrafluorobenzoates having two ortho-F atoms $\mathbf{4 b}, \mathbf{4 c}$ and 4d proved to be also good coupling partners and could undergo the decarboxylative cross-coupling reactions with a range of aryl iodides effectively to furnish the desired coupling products $\mathbf{5 f}-\mathbf{5 p}$ in good to excellent yields. The method provides a quite general and practical route for the synthesis of polyfluorobiaryls having various functionalities under green conditions.

To verify whether the observed catalysis was due to the heterogeneous catalyst MCM-41-1,10-Phen-CuI or to a leached copper species in solution, the reaction of $\mathrm{C}_{6} \mathrm{~F}_{5} \mathrm{COOK}(1.5$ $\mathrm{mmol})$ with $\mathrm{PhI}(1.0 \mathrm{mmol})$ in diglyme $(1.5 \mathrm{~mL})$ was carried out until an approximately $50 \%$ conversion of $\mathrm{PhI}$ was reached. Then the MCM-41-1,10-Phen-CuI catalyst was removed from the reaction mixture by hot filtration ${ }^{27}$ and the filtrate was allowed to react further by addition of $\mathrm{C}_{6} \mathrm{~F}_{5} \mathrm{COOK}(0.8 \mathrm{mmol})$ at $130^{\circ} \mathrm{C}$ under $\mathrm{Ar}$ atmosphere for $20 \mathrm{~h}$. In this case, no significant increase in conversion of $\mathrm{PhI}$ was observed, indicating that leached copper species from the supported catalyst (if any) are not responsible for the observed activity. It was confirmed by ICP-AES analysis that no copper species could be detected in the filtrate (below the detection limit). These results rule out any contribution to the observed catalysis from a homogeneous copper species demonstrating that the catalyst was stable during the reaction and the observed catalysis was intrinsically heterogeneous.

A plausible mechanism for the heterogeneous copper(I)catalyzed decarboxylative cross-coupling of potassium 


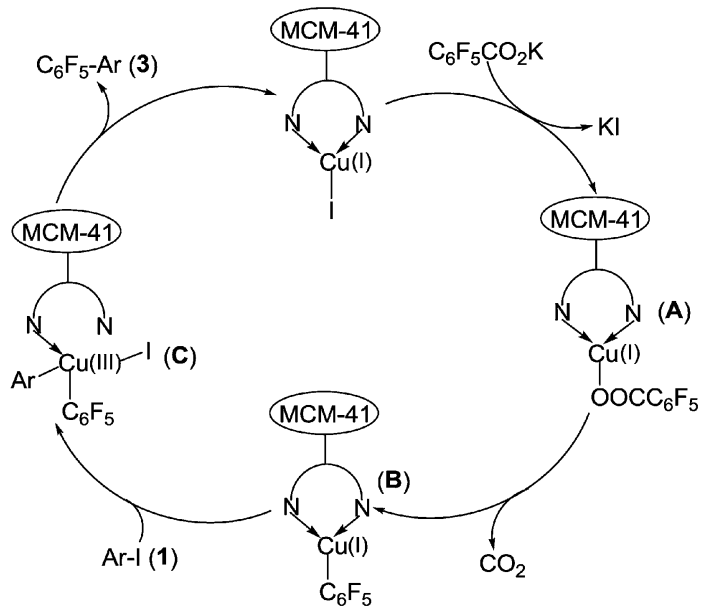

Scheme 3 Plausible mechanism for the heterogeneous Cu-catalyzed decarboxylative cross-coupling reaction.

polyfluorobenzoates with aryl halides is illustrated in Scheme 3. Firstly, the reaction of MCM-41-Phen-CuI with $\mathrm{C}_{6} \mathrm{~F}_{5} \mathrm{CO}_{2} \mathrm{~K}$ affords an MCM-41-immobilized 1,10-phenanthroline-Cu(I)OCOC $_{6} \mathrm{~F}_{5}$ intermediate $\mathrm{A}$, which then undergoes decarboxylation via a four-membered-ring transition state to form an MCM-41-immobilized 1,10-phenanthroline- $\mathrm{Cu}(\mathrm{I})-\mathrm{C}_{6} \mathrm{~F}_{5}$ intermediate $\mathbf{B}$. The oxidative addition of $\mathrm{Ar}-\mathrm{I} \mathbf{1}$ to intermediate $\mathbf{B}$ gives an MCM-41-immobilized 1,10-phenanthroline-ArCu(III)I$\mathrm{C}_{6} \mathrm{~F}_{5}$ intermediate $\mathbf{C}$. Finally, reductive elimination of intermediate $\mathbf{C}$ produces the desired product $\mathbf{3}$ and regenerates the MCM-41-Phen-CuI complex to complete the catalytic cycle.

For the practical application of a heterogeneous catalyst system its stability and recyclability are important factors. We next examined the reusability and stability of the MCM-41Phen-CuI complex by using coupling reaction between iodobenzene $(0.5 \mathrm{mmol})$ and $\mathrm{C}_{6} \mathrm{~F}_{5} \mathrm{CO}_{2} \mathrm{~K}(0.75 \mathrm{mmol})$ in diglyme $(0.5$ $\mathrm{mL}$ ) in the presence of $10 \mathrm{~mol} \%$ of MCM-41-Phen-CuI at $130{ }^{\circ} \mathrm{C}$ under argon atmosphere for $24 \mathrm{~h}$. After carrying out the reaction, the catalyst was separated by simple filtration and washed with distilled water and EtOH. After being air-dried, it can be reused directly without further purification. The recovered

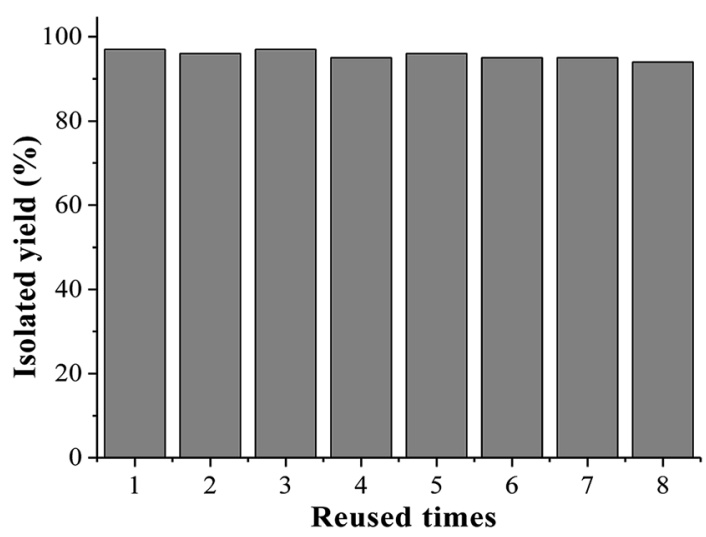

Fig. 1 Recycle of MCM-41-Phen-Cul complex. catalyst was used in the next run, and almost the same yield of 3a was obtained for 8 consecutive cycles (Fig. 1). In addition, copper leaching in the heterogeneous catalyst was also determined by ICP-AES analysis on the recovered catalyst after eight consecutive runs, which revealing almost the same copper content as the fresh one. In our opinion, the excellent catalytic activity and reusability of the copper catalyst relates to the efficient site isolation, to the optimal dispersion of the active sites on the inner channel walls and to the relatively strong interaction between the bidentate 1,10-phenanthroline ligand and the copper centre supported on the MCM-41. The result is important from the standpoint of green and sustainable chemistry.

\section{Conclusions}

In summary, we have successfully developed a novel, practical and environmentally friendly method for the synthesis of polyfluorobiaryls through the decarboxylative cross-coupling of readily accessible and nonvolatile potassium polyfluorobenzoates with aryl iodides or bromides by using an MCM-41-immobilized 1,10-phenanthroline-copper(I) complex [MCM-41-Phen-CuI] as catalyst. This heterogeneous copper catalyst could be easily prepared by a simple procedure from commercially available and inexpensive reagents and exhibited the same catalytic activity as the homogeneous CuI/Phen system. The reactions generated a variety of polyfluorobiaryls in good to excellent yields and were applicable to various polyfluorobenzoate salts and a wide range of aryl iodides or bromides. In addition, this methodology offers the competitiveness of recyclability of the copper catalyst without any decreases in activity, and the copper catalyst can be readily recovered by a simple filtration and reused at least 8 cycles, thus making this procedure economically and environmentally more acceptable.

\section{Experimental}

All chemicals were reagent grade and used as purchased. All solvents were dried and distilled before use. The MCM-41-Phen$\mathrm{CuCl}$ [A], MCM-41-Phen-CuBr [B], MCM-41-Phen-CuI [C], MCM41-Phen- $\mathrm{CuCl}_{2}$ [D], MCM-41-Phen-CuBr 2 [E] and MCM-41-Phen$\mathrm{Cu}(\mathrm{OAc})_{2}[\mathbf{F}]$ were prepared according to our previous procedure, ${ }^{24}$ the copper contents were determined to be $0.73 \mathrm{mmol}$ $\mathrm{g}^{-1}, 0.71 \mathrm{mmol} \mathrm{g}^{-1}, 0.74 \mathrm{mmol} \mathrm{g}^{-1}, 0.68 \mathrm{mmol} \mathrm{g}^{-1}, 0.70 \mathrm{mmol}$ $\mathrm{g}^{-1}$ and $0.67 \mathrm{mmol} \mathrm{g}^{-1}$, respectively. The products were purified by flash chromatography on silica gel. Mixture of EtOAc and hexane was generally used as eluent. ${ }^{1} \mathrm{H}$ NMR spectra were recoded on a Bruker Avance $400 \mathrm{MHz}$ spectrometer with TMS as an internal standard in $\mathrm{CDCl}_{3}$ as solvent. ${ }^{13} \mathrm{C}$ NMR spectra (100 $\mathrm{MHz}$ ) were recorded on a Bruker Avance $400 \mathrm{MHz}$ spectrometer in $\mathrm{CDCl}_{3}$ as solvent. ${ }^{19} \mathrm{~F} \mathrm{NMR}$ spectra $(376 \mathrm{MHz})$ were recorded on a Bruker Avance $400 \mathrm{MHz}$ spectrometer in $\mathrm{CDCl}_{3}$ as solvent with trifluorotoluene (TFT) $(\delta=-67.73 \mathrm{ppm})$ as an external standard. Melting points are uncorrected. Copper content was determined with inductively coupled plasma atom emission Atomscan16 (ICP-AES, TJA Corporation). HRMS spectra were 
recorded on a Q-Tof spectrometer with micromass MS software using electrospray ionization (ESI).

\subsection{General procedure for the decarboxylative cross-coupling of potassium pentafluorobenzoate with various aryl iodides}

MCM-41-Phen-CuI (67 mg, $0.05 \mathrm{mmol}$ ), potassium pentafluorobenzoate $(188 \mathrm{mg}, 0.75 \mathrm{mmol})$ and aryl iodide 1 (0.50 $\mathrm{mmol}$ ) (if solid) were placed in an oven-dried $10 \mathrm{~mL}$ Schlenk tube, the reaction vessel was evacuated and filled with argon for three times. Then aryl iodide $(0.50 \mathrm{mmol})$ (if liquid) and diglyme $(0.5 \mathrm{~mL})$ were added with a syringe under a counter flow of argon. The vessel was sealed with a screw cap, stirred at room temperature for $10 \mathrm{~min}$, and then connected to the Schlenk line filled with argon. The reaction mixture was stirred at $130{ }^{\circ} \mathrm{C}$ for $24 \mathrm{~h}$. Upon completion of the reaction, the mixture was cooled to room temperature and diluted with ethyl acetate $(20 \mathrm{~mL})$ and filtered. The MCM-41-Phen-CuI complex was washed with distilled water $(2 \times 5 \mathrm{~mL})$ and EtOH $(2 \times 5 \mathrm{~mL})$, and reused in the next run. The organic layers were washed with water $(2 \times 20$ $\mathrm{mL}$ ), and then with brine, dried over $\mathrm{MgSO}_{4}$, and filtered. The solvents were removed via rotary vapor and the residue was purified by flash column chromatography on silica gel to provide the product 3 .

\subsection{General procedure for the decarboxylative cross-coupling of potassium pentafluorobenzoate with various aryl bromides}

MCM-41-Phen-CuI (135 mg, $0.1 \mathrm{mmol}$ ), potassium pentafluorobenzoate $(188 \mathrm{mg}, 0.75 \mathrm{mmol})$ and aryl bromide $2(0.50$ $\mathrm{mmol}$ ) (if solid) were placed in an oven-dried $10 \mathrm{~mL}$ Schlenk tube, the reaction vessel was evacuated and filled with argon for three times. Then aryl bromide $(0.50 \mathrm{mmol})$ (if liquid) and diglyme $(0.8 \mathrm{~mL})$ were added with a syringe under a counter flow of argon. The vessel was sealed with a screw cap, stirred at room temperature for $10 \mathrm{~min}$, and then connected to the Schlenk line filled with argon. The reaction mixture was stirred at $130{ }^{\circ} \mathrm{C}$ for 24-36 h. Upon completion of the reaction, the mixture was cooled to room temperature and diluted with ethyl acetate (20 $\mathrm{mL})$ and filtered. The MCM-41-Phen-CuI complex was washed with distilled water $(2 \times 5 \mathrm{~mL})$ and $\mathrm{EtOH}(2 \times 5 \mathrm{~mL})$, and reused in the next run. The organic layers were washed with water $(2 \times$ $20 \mathrm{~mL}$ ), and then with brine, dried over $\mathrm{MgSO}_{4}$, and filtered. The solvents were removed via rotary vapor and the residue was purified by flash column chromatography on silica gel to provide the product 3 .

\subsection{General procedure for the decarboxylative cross-coupling of potassium perfluorobenzoates with various aryl iodides}

MCM-41-Phen-CuI (135 mg, $0.1 \mathrm{mmol})$, potassium perfluorobenzoate $4(0.75 \mathrm{mmol})$ and aryl iodide $1(0.50 \mathrm{mmol})$ (if solid) were placed in an oven-dried $10 \mathrm{~mL}$ Schlenk tube, the reaction vessel was evacuated and filled with argon for three times. Then aryl iodide $(0.50 \mathrm{mmol})$ (if liquid) and DMAc $(0.8$ $\mathrm{mL}$ ) were added with a syringe under a counter flow of argon. The vessel was sealed with a screw cap, stirred at room temperature for $10 \mathrm{~min}$, and then connected to the Schlenk line filled with argon. The reaction mixture was stirred at $160^{\circ} \mathrm{C}$ for
$24 \mathrm{~h}$. Upon completion of the reaction, the mixture was cooled to room temperature and diluted with ethyl acetate $(20 \mathrm{~mL})$ and filtered. The MCM-41-Phen-CuI complex was washed with distilled water $(2 \times 5 \mathrm{~mL})$ and EtOH $(2 \times 5 \mathrm{~mL})$, and reused in the next run. The organic layers were washed with water $(2 \times 20$ $\mathrm{mL}$ ), and then with brine, dried over $\mathrm{MgSO}_{4}$, and filtered. The solvents were removed via rotary vapor and the residue was purified by flash column chromatography on silica gel to provide the desired product 5 .

\section{Conflicts of interest}

There are no conflicts of interest to declare.

\section{Acknowledgements}

We thank the National Natural Science Foundation of China (Project No. 21272044) and Project of innovation for enhancing Guangdong Pharmaceutical University, provincial experimental teaching demonstration center of chemistry \& chemical engineering for financial support.

\section{References}

1 (a) A. Zahn, C. Brotschi and C. J. Leumann, Chem.-Eur. J., 2005, 11, 2125-2129; (b) R. E. Mewshaw, R. J. Edsall Jr, C. Yang, E. S. Manas, Z. B. Xu, R. A. Henderson, J. C. Keith Jr and H. A. Harris, J. Med. Chem., 2005, 48, 3953-3979; (c) S. Purser, P. R. Moor, S. Swallow and V. Gouverneur, Chem. Soc. Rev., 2008, 37, 320-330; (d) M. de Candia, F. Liantonio, A. Carotti, R. De Cristofaro and C. Altomare, J. Med. Chem., 2009, 52, 1018-1028.

2 (a) J. R. Nitschke and T. D. Tilley, J. Am. Chem. Soc., 2001, 123, 10183-10190; (b) Y. Sakamoto, T. Suzuki, A. Miura, H. Fujikawa, S. Tokito and Y. Taga, J. Am. Chem. Soc., 2000, 122, 1832-1833; (c) V. A. Montes, G. Li, R. Pohl, J. Shinar and P. Anzenbacher, Adv. Mater., 2004, 16, 2001-2003; (d) P. Zacharias, M. C. Gather, M. Rojahn, O. Nuyken and K. Meerholz, Angew. Chem., Int. Ed., 2007, 46, 4388-4392.

3 (a) H. Amii and K. Uneyama, Chem. Rev., 2009, 109, 21192183; (b) S. M. Senaweera, A. Singh and J. D. Weaver, J. Am. Chem. Soc., 2014, 136, 3002-3005.

4 (a) T. Korenaga, T. Kosaki, R. Fukumura, T. Ema and T. Sakai, Org. Lett., 2005, 7, 4915-4917; (b) T. Kinzel, Y. Zhang and S. L. Buchwald, J. Am. Chem. Soc., 2010, 132, 14073-14075.

5 (a) H. J. Frohn, N. Y. Adonin, V. V. Bardin and V. F. Starichenko, Tetrahedron Lett., 2002, 43, 8111-8114; (b) H. J. Frohn, N. Y. Adonin, V. V. Bardin and V. F. Starichenko, J. Fluorine Chem., 2002, 117, 115-120.

6 P. L. Coe and G. M. Pearl, J. Organomet. Chem., 1971, 31, 5557.

7 R. J. DePasquake and C. Tamborski, J. Org. Chem., 1969, 34, 1736-1740.

8 (a) M. Lafrance, C. N. Rowley, T. K. Woo and K. Fagnou, J. Am. Chem. Soc., 2006, 128, 8754-8756; (b) M. Lafrance, D. Shore and K. Fagnou, Org. Lett., 2006, 8, 5097-5100; (c) 
H.-Q. Do and O. Daugulis, J. Am. Chem. Soc., 2008, 130, 11281129; (d) H.-Q. Do, R. M. Kashif and O. Daugulis, J. Am. Chem. Soc., 2008, 130, 15185-15192.

9 Y. Wei, J. Kan, M. Wang, W. Su and M. Hong, Org. Lett., 2009, 11, 3346-3349.

10 H. Fan, Y. Shang and W. Su, Eur. J. Org. Chem., 2014, 33233327.

11 X. Zhu, F. Li and W. Su, Tetrahedron Lett., 2013, 54, 12851289.

12 Z. Fu, Q. Xiong, W. Zhang, Z. Li and H. Cai, Tetrahedron Lett., 2015, 56, 123-126.

13 (a) O. Baudoin, Angew. Chem., Int. Ed., 2007, 46, 1373-1375; (b) L. J. Goossen, N. Rodriguez and K. Goossen, Angew. Chem., Int. Ed., 2008, 47, 3100-3120; (c) L. J. Goossen, G. Deng and L. M. Levy, Science, 2006, 313, 662-664; (d) D. Tanaka, S. P. Romeril and A. G. Myers, J. Am. Chem. Soc., 2005, 127, 10323-10333; (e) C. Wang, I. Piel and F. Glorius, J. Am. Chem. Soc., 2009, 131, 4194-4195; $(f)$ J. D. Weaver, A. Recio, A. J. Grenning and J. A. Tunge, Chem. Rev., 2011, 111, 1846-1913; (g) W. L. Dzik, P. P. Lange and L. J. Goossen, Chem. Sci., 2012, 3, 26712678; (h) L. J. Goossen and K. Goossen, Top. Organomet. Chem., 2013, 44, 121-141.

14 (a) J.-M. Becht, C. Catala, C. Le Drian and A. Wagner, Org. Lett., 2007, 9, 1781-1784; (b) A. Voutchkova, A. Coplin, N. E. Leadbeater and R. H. Crabtree, Chem. Commun., 2008, 6312-6314; (c) R. Shang, Y. Fu, Y. Wang, Q. Xu, H.-Z. Yu and L. Liu, Angew. Chem., Int. Ed., 2009, 48, 93509354; (d) R. Shang, Q. Xu, Y.-Y. Jiang, Y. Wang and L. Liu, Org. Lett., 2010, 12, 1000-1003; (e) L. W. Sardzinski, W. C. Wertjes, A. M. Schnaith and D. Kalyani, Org. Lett., 2015, 17, 1256-1259.

15 H. Zhao, Y. Wei, J. Xu, J. Kan, W. Su and M. Hong, J. Org. Chem., 2011, 76, 882-893.

16 (a) C. E. Garrett and K. Prasad, Adv. Synth. Catal., 2004, 346, 889-900; (b) C. J. Welch, J. Albaneze-Walker, W. R. Leonard, M. Biba, J. DaSilva, D. Henderson, B. Laing, D. J. Mathre, S. Spencer, X. Bu and T. Wang, Org. Process Res. Dev., 2005, 9, 198-205; (c) S. Benyahya, F. Monnier, M. Wong Chi Man, C. Bied, F. Ouazzani and M. Taillefer, Adv. Synth. Catal., 2008, 350, 2205-2208; (d) S. Benyahya, F. Monnier, M. Wong Chi Man, C. Bied, F. Ouazzani and M. Taillefer, Green Chem., 2009, 11, 1121-1123; (e) P.-H. Li and L. Wang, Adv. Synth. Catal., 2006, 348, 681-685; (f) J. Yang, P. Li and L. Wang, Tetrahedron, 2011, 67, 5543-5549; $(g)$ P. Li, L. Wang, L. Zhang and G.-W. Wang, Adv. Synth. Catal., 2012, 354, 1307-1318; (h) L. Zhang, P. Li, C. Liu, J. Yang, M. Wang and L. Wang, Catal. Sci. Technol., 2014, 4, 1979-1988.

17 For selected reviews, see: $(a)$ N. T. S. Phan, M. V. D. Sluys and C. W. Jones, Adv. Synth. Catal., 2006, 348, 609-679; (b) L. Yin and J. Liebscher, Chem. Rev., 2007, 107, 133-173; (c)
R. Akiyama and S. Kobayashi, Chem. Rev., 2009, 109, 594642; (d) M. J. Climent, A. Corma and S. Iborra, Chem. Rev., 2011, 111, 1072-1133; (e) A. Molnar, Chem. Rev., 2011, 111, 2251-2320; (f) M. Yoon, R. Srirambalaji and K. Kim, Chem. Rev., 2012, 112, 1196-1231.

18 (a) C. T. Kresge, M. E. Leonowicz, W. J. Roth, J. C. Vartuli and J. S. Beck, Nature, 1992, 359, 710-712; (b) J. S. Beck, J. C. Vartuli, W. J. Roth, M. E. Leonowicz, C. T. Kresge, K. D. Schmitt, C. T.-W. Chu, D. H. Olson, E. W. Sheppard, S. B. McCullen, J. B. Higgins and J. L. Schlenker, J. Am. Chem. Soc., 1992, 114, 10834-10843; (c) W. Zhou, J. M. Thomas, D. S. Shephard, B. F. G. Johnson, D. Ozkaya, T. Maschmeyer, R. G. Bell and Q. Ge, Science, 1998, 280, 705-708.

19 For selected examples, see: (a) P. C. Mehnert, D. W. Weaver and J. Y. Ying, J. Am. Chem. Soc., 1998, 120, 12289-12296; (b) K. Mukhopadhyay, B. R. Sarkar and R. V. Chaudhari, J. Am. Chem. Soc., 2002, 124, 9692-9693; (c) J. Y. Ying, C. P. Mehnert and M. S. Wong, Angew. Chem., Int. Ed., 1999, 38, 56-77; (d) M. Cai, G. Zheng and G. Ding, Green Chem., 2009, 11, 1687-1693; (e) M. Cai, J. Peng, W. Hao and G. Ding, Green Chem., 2011, 13, 190-196; (f) W. Hao, H. Liu, L. Yin and M. Cai, J. Org. Chem., 2016, 81, 42444251; $(g)$ F. Havasi, A. Ghorbani-Choghamarani and F. Nikpour, New J. Chem., 2015, 39, 6504-6512.

20 (a) S.-G. Shyu, S.-W. Cheng and D.-L. Tzou, Chem. Commun., 1999, 2337-2338; (b) Y. Yang and R. M. Rioux, Chem. Commun., 2011, 47, 6557-6559.

21 (a) C. D. Nunes, A. A. Valente, M. Pillinger, A. C. Fernandes, C. C. Romao, J. Rocha and I. S. Goncalves, J. Mater. Chem., 2002, 12, 1735-1742; (b) M. Jia, A. Seifert and W. R. Thiel, Chem. Mater., 2003, 15, 2174-2180.

22 (a) A. Corma, E. Gutierrez-Puebla, M. Iglesias, A. Monge, S. Perez-Ferreras and F. Sanchez, Adv. Synth. Catal., 2006, 348, 1899-1907; (b) A. Corma, C. Gonzalez-Arellano, M. Iglesias and F. Sanchez, Angew. Chem., Int. Ed., 2007, 46, 7820-7822; (c) G. Villaverde, A. Corma, M. Iglesias and F. Sanchez, ACS Catal., 2012, 2, 399-406.

23 (a) R. Xiao, H. Zhao and M. Cai, Tetrahedron, 2013, 69, 54445545; (b) H. Zhao, W. He, R. Yao and M. Cai, Adv. Synth. Catal., 2014, 356, 3092-3098; (c) M. Cai, R. Yao, L. Chen and H. Zhao, J. Mol. Catal. A: Chem., 2014, 395, 349-354; (d) H. Zhao, Y. Jiang, Q. Chen and M. Cai, New J. Chem., 2015, 39, 2106-2111; (e) H. Zhao, W. He, L. Wei and M. Cai, Catal. Sci. Technol., 2016, 6, 1488-1495.

24 Y. Lin, M. Cai, Z. Fang and H. Zhao, RSC Adv., 2016, 6, 8518685193.

25 M. H. Lim and A. Stein, Chem. Mater., 1999, 11, 3285-3295. 26 M.-J. Li, Z. Chen, V. Wing-Wah Yam and Y. Zu, ACS Nano, 2008, 2, 905-912.

27 H. E. B. Lempers and R. A. Sheldon, J. Catal., 1998, 175, 6269. 